\title{
The POLR2E rs3787016 polymorphism is associated with susceptibility to and prognosis of gastric cancer
}

\author{
Ya-Kun ZHANG ${ }^{1, *}$, Li-Ling WU ${ }^{2,3, *}$, Ting-Ting LI ${ }^{4}$, Di-Yong CAO ${ }^{5}$, Qian ZHENG ${ }^{5}$, Lu LIU ${ }^{5, *}$ \\ ${ }^{1}$ Department of Oncology, Affiliated Hospital of North Sichuan Medical College, North Sichuan Medical College, Nanchong, China; ${ }^{2}$ Department \\ of Pharmacy, Nanchong Center Hospital, The Second Clinical Medical College, North Sichuan Medical College, Nanchong, China; ${ }^{3}$ Nanchong \\ Key Laboratory of Individualized Drug Therapy, Nanchong, China; ${ }^{4}$ Department of Oncology, Nanchong Center Hospital, The Second Clinical \\ Medical College, North Sichuan Medical College, Nanchong, China; ${ }^{5}$ Medical Functional Experiment Center, School of Medical Sciences, North \\ Sichuan Medical College, Nanchong, China
}

${ }^{*}$ Correspondence: liuludoctor88@nsmc.edu.cn

"Contributed equally to this work.

Received November 25, 2020 / Accepted February 22, 2021

\begin{abstract}
Long non-coding RNAs (lncRNAs) have been proposed as promising diagnostic and prognostic biomarkers for cancer. We investigated the associations of RNA polymerase II subunit E (POLR2E) rs3787016 polymorphism with the risk and prognosis of gastric cancer (GC). The study subjects included 368 GC patients who underwent surgical resection and 294 healthy volunteers, adjusted for age, gender, smoking status, alcohol status, and Helicobacter pylori infection status. The data was subjected to logistic regression analyses and revealed that the subjects carrying AA genotype of rs3787016 in POLR2E had a significant 1.85-1.98-fold increased risk of GC when compared with those carrying GG genotype (adjusted $\mathrm{OR}=1.979,95 \% \mathrm{CI}=1.198-3.267 ; \mathrm{p}=0.008$ ) or those carrying AG/GG genotypes (adjusted $\mathrm{OR}=1.847,95 \% \mathrm{CI}=1.222-2.793$; $\mathrm{p}=0.004)$. For the GC patients, the AA genotype of rs3787016 was significantly correlated with poorly differentiated GC $(\mathrm{p}=0.018)$, advanced TNM stage $(\mathrm{p}=0.023)$, higher depth of invasion $(\mathrm{p}=0.022)$, positive lymph node metastasis $(\mathrm{p}=0.01)$, and worse overall survival (OS; $\mathrm{p}=0.004$ ). Multivariate analysis confirmed that the POLR2E rs3787016 polymorphism is an independent prognostic factor for $\mathrm{GC}(\mathrm{HR}=1.668,95 \% \mathrm{CI}=1.058-2.631 ; \mathrm{p}=0.028)$. Our cumulative results thus suggest that the presence of POLR2E rs3787016 polymorphism could serve as a genetic factor that affects the susceptibility to and the prognosis of GC.
\end{abstract}

Key words: POLR2E, rs3787016, gastric cancer, overall survival, prognosis

Based on the latest cancer statistics, gastric cancer is the fifth most frequently diagnosed cancer, and the third leading cause of cancer-related death worldwide [1]. Approximately 679,100 new gastric cancer cases and 498,000 deaths from gastric cancer were recorded in China alone in 2015, which rank it second in cancer incidence and third in cancer mortality in the world, respectively [2]. Helicobacter pylori (H. pylori), as the main risk factor for gastric cancer, contributes to almost $90 \%$ of the new cases of non-cardia gastric cancer. [3]. Other factors, including genetic polymorphisms, dietary habits, smoking, and alcohol consumption, also play important roles in the development of gastric cancer $[4,5]$. With surgical resection along with radiotherapy or platinumbased chemotherapy as the golden standard of the firstline treatment, the 5-year survival rate of gastric cancer in China is only approximately $30 \%$ due to the diagnoses at the advanced stages of the disease [6]. It is therefore urgent to discover novel biomarkers for effective screening and detection at an early stage of gastric cancer.

Several studies have demonstrated that long non-coding RNAs (lncRNAs) may be involved in the regulation of tumor pathogenesis and tumor progression as anti-oncogenes or proto-oncogenes in various types of cancer [7-9]. Affecting gene expressions and functions, single nucleotide polymorphisms (SNPs) especially in lncRNAs are believed to be able to influence the functions of multiple biological pathways that may be involved in carcinogenesis and progression in humans. For example, lncRNA H19 is one of the most important lncRNAs in cancer that has been extensively studied. Liu et al. reviewed 60 eligible studies comprising 20,763 cases and 27,403 controls [10], and the results indicated that H19 rs217727 (A>T), rs2839698 (G>A), and rs2107425 (C>T) polymorphisms were significantly associated with increased risk of cancer. Moreover, H19 rs2839698 polymorphism is 
associated with the prognosis of hepatocellular cancer (HCC) and gastric cancer $[11,12]$.

According to a recent report, SNP rs3787016 (A>G), localized in the fourth intron of the RNA polymerase II subunit E (POLR2E) lncRNA gene [13], may serve as a genetic risk factor for different types of cancer including prostate cancer (PCa) [14-16], lung cancer [17], liver cancer [17], breast cancer [18, 19], cervical cancer [18], esophageal cancer [20], papillary thyroid carcinoma [21], and glioma [22]. Although the literature presents conflicting notions, it is believed that rs3787016 may serve as a genetic factor that affects the susceptibility to cancer. Yet no study has investigated the role of POLR2E rs3787016 polymorphism in the diagnosis and prognosis of gastric cancer. Thus, we select it as a candidate for evaluating the risk and prognosis of gastric cancer in a Chinese population.

\section{Patients and methods}

Ethical statement. The present study was approved by the ethics committee of the Affiliated Hospital of North Sichuan Medical College and the Second Clinical School of North Sichuan Medical College (Nanchong Center Hospital). All participants provided written informed consent approving the use of their samples and clinical data for research purposes.

Study subjects. This study recruited 368 patients with gastric cancer who underwent surgical resection as cases and 294 healthy volunteers as controls from a Chinese population between December 2014 and May 2018. All the gastric cancer cases were newly diagnosed and histopathologically confirmed. The histological type of tumor was evaluated by the World Health Organization (WHO) criteria, and the tumor stages were classified according to the guidelines of the Cancer Staging Manual of the American Joint Committee on Cancer system ( $7^{\text {th }}$ edition). Patients with secondary or recurrent tumors were excluded. None of them received chemotherapy, radiotherapy, or immunotherapy before surgery. Meanwhile, all controls were matched to cases in terms of age and gender. The demographic and baseline clinical characteristics of all participants were recorded. Phone surveys and clinical examinations were conducted at least every three months for a follow-up duration of three years in total.

DNA extraction and SNP genotyping. The buccal epithelial cells were collected with a sterile wooded spatula after the patients rinsed their mouths with a mouthwash containing $3 \%$ glucose solution. Then, the DNA samples were extracted using QIAamp DNA Mini Kit (QIAGEN, Germany) and stored at $-20^{\circ} \mathrm{C}$ until further use. The POLR2E rs3787016 polymorphism was detected by Taqman SNP Genotyping Assay (Thermo Fisher, USA) with 50 ng DNA amplified in $25 \mu$. The following thermal cycling conditions for quantitative real-time PCR (qRT-PCR) were used: $95^{\circ} \mathrm{C}$ for 10 min for enzyme activation of AmpliTaq Gold, followed by
40 cycles of denaturation at $95^{\circ} \mathrm{C}$ for $15 \mathrm{~s}$ and annealing/ extension at $65^{\circ} \mathrm{C}$ for $1 \mathrm{~min}$.

Statistical analyses. The statistical analyses were performed using SPSS software (version 19.0). The differences in the allele frequencies between cases and controls were evaluated by the $\chi^{2}$ test. Logistic regression was used to account for the association between genotypes and gastric cancer, adjusted by age, gender, smoking, drinking, and $H$. pylori infection status. The odds ratio (OR) and its $95 \%$ confidence interval (CI) were calculated accordingly. The dominant and recessive models were tested for the minor allele with the heterozygote pooled with one homozygote against the other. The HardyWeinberg equilibrium (HWE) of genotype distributions in the controls was also tested by the $\chi^{2}$ test. In addition, we evaluated our findings by performing a false-positive report probability (FPRP) analysis. FPRP $<0.2$ was considered noteworthy. The endpoint for the follow-up was the overall survival (OS). Kaplan-Meier curves were plotted and groups were compared by the log-rank test. The effect of clinical variables on the survival outcome was evaluated via multivariate analysis using a Cox proportional hazards regression model. A two-tailed $\mathrm{p}<0.05$ indicated statistical significance.

\section{Results}

Characteristics of the study population. The baseline characteristics of the 368 GC patients and 294 healthy volunteers are summarized in Table 1. The distributions of age, gender, smoking, and drinking status were comparable in the case and control groups ( $\mathrm{p}>0.05)$. However, the H. pylori positive rate was significantly higher in cancer patients than in controls (69.0\% vs. $57.8 \%, \mathrm{p}=0.014)$.

Associations of POLR2E rs3787016 polymorphism with gastric cancer risk. TAs presented in Table 2, there was no significant deviation from HWE $(\mathrm{p}=0.247)$ in the control group. The results of logistic regression revealed that homozygous genotype AA of rs3787016 was significantly associated with an increased risk of gastric cancer in the additive model ( $\mathrm{OR}=2.013,95 \% \mathrm{CI}=[1.220-3.277]$; $\mathrm{p}=0.005$ ), compared to the homozygous genotype GG and it also suggested an increased risk of gastric cancer associated with genotype AA in the recessive model $(\mathrm{OR}=1.887$, $95 \% \mathrm{CI}=[1.249-2.855] ; \mathrm{p}=0.002)$. The findings in the recessive model were considered noteworthy $(\mathrm{FPRP}=0.147 ; 0.1$ as a prior probability), while the additive model may confront false positive ( $\mathrm{FPRP}=0.271 ; 0.1$ as a prior probability). After adjusting for age, gender, smoking, drinking, and $H$. pylori infection status in a multivariate logistic regression model, genotype AA still showed a significant increased risk of gastric cancer when compared to genotype GG (adjusted $\mathrm{OR}=1.979,95 \% \mathrm{CI}=[1.198-3.267] ; \mathrm{p}=0.008)$ or to $\mathrm{AG} / \mathrm{GG}$ pooled genotypes (adjusted $\mathrm{OR}=1.847,95 \% \mathrm{CI}=[1.222$ 2.793]; $p=0.004)$. In addition, no significant differences were noted for AG vs. GG in the additive model and AG+AA vs. GG in the dominant model between groups. 
Associations between POLR2E rs3787016 polymorphism and clinicopathological variables of gastric cancer patients. As shown in Table 3, more patients were diagnosed at an advanced TNM stage (III-IV, 60.9\%), had a higher depth of invasion (T3-T4, 70.7\%), had positive lymph node metastasis $(65.8 \%)$. Less than half of patients $(46.7 \%)$ showed poorly differentiated tumors and only a few patients showed larger tumor size ( $\geq 5 \mathrm{~cm}, 26.6 \%)$ and positive distant metastasis (18.5\%). Our results thus revealed that genotype AA of rs3787016 was significantly correlated with poorly differentiated gastric cancer $(\mathrm{p}=0.018)$, advanced TNM stage $(p=0.023)$, higher depth of invasion $(p=0.022)$, and positive lymph node metastasis $(\mathrm{p}=0.01)$. No association was suggested between $P O L R 2 E$ rs3787016 polymorphism and other clinical variables such as age, gender, smoking and drinking history, $H$. pylori status, tumor size, and distant metastasis.

Association of POLR2E rs3787016 polymorphism with the survival of gastric cancer. Our results revealed that the subjects carrying genotype AA of rs3787016 had significantly worse OS $(p=0.004)$ in comparison with those carrying the genotype AG/GG (Figure 1, $\mathrm{p}=0.004$ ). The univariate Cox regression analyses indicated that the genotype AA $(\mathrm{p}=0.001)$, poorly differentiated type $(\mathrm{p}=0.031)$, advanced TNM stage $(\mathrm{p}=0.001)$, and positive lymph node metastasis $(\mathrm{p}=0.037)$ were significantly associated with poor OS, but not the same case for age, gender, smoking and drinking, H. pylori infection status, tumor size, depth of invasion, or distant metastasis (Table 4). Further multivariate analysis revealed that genotype AA was effective for predicting overall survival, after adjusting for covariates (Table 5, $\mathrm{p}=0.028$ ).

\section{Discussion}

LncRNAs hold great potential as therapeutic targets and novel biomarkers for cancer, not only because they play important roles in tumor pathogenesis and progression [7-9] but also because of their characteristics of tissue- or cancer-specific expression and relative stability in various sample types, including the plasma, tissues, saliva, or urine [23]. To date, more than 30 lncRNAs have been reported to be directly involved in cell migration, apoptosis, epithelial to

Table 1. Baseline characteristics of participants.

\begin{tabular}{lccc}
\hline & Case $(\mathbf{n}=\mathbf{3 6 8})$ & Control $(\mathbf{n}=\mathbf{2 9 4})$ & p-value \\
\hline $\begin{array}{l}\text { Age (years, mean } \pm \mathrm{SD}) \\
\text { Age group (years), } \mathrm{n}(\%)\end{array}$ & $55.4 \pm 13.2$ & $54.8 \pm 16.6$ & 0.164 \\
$\quad \leq 60$ & $204(55.4)$ & $176(59.9)$ & 0.340 \\
$\quad>60$ & $164(44.6)$ & $118(40.1)$ & \\
Gender, n (\%) & & & \\
$\quad$ Male & $220(59.8)$ & $186(63.3)$ & 0.446 \\
$\quad$ Female & $148(40.2)$ & $108(36.7)$ & \\
Smoking status, $\mathrm{n}(\%)$ & & & 0.151 \\
$\quad$ Ever & $162(44.0)$ & $110(37.4)$ & \\
$\quad$ Never & $206(56.0)$ & $184(62.6)$ & \\
Drinking status, $\mathrm{n}(\%)$ & & & \\
$\quad$ Ever & $264(71.7)$ & $193(65.6)$ & 0.165 \\
$\quad$ Never & $104(28.3)$ & $101(34.4)$ & \\
Helicobacter pylori status, $\mathrm{n}(\%)$ & & & \\
$\quad$ Negative & $114(31.0)$ & $124(42.2)$ & $0.014^{*}$ \\
$\quad$ Positive & $254(69.0)$ & $170(57.8)$ & \\
\hline
\end{tabular}

Note: ${ }^{*}$ indicates p-value $<0.05$.

Table 2. Association between POLR2E rs3787016 polymorphism and gastric cancer risk.

\begin{tabular}{|c|c|c|c|c|c|c|c|c|c|c|c|c|}
\hline \multirow{2}{*}{ Genotype } & \multirow{2}{*}{$\begin{array}{l}\begin{array}{c}\text { Patient } \\
(\mathrm{n}=368)\end{array} \\
\text { No. }(\%)\end{array}$} & \multirow{2}{*}{$\begin{array}{c}\begin{array}{c}\text { Control } \\
(\mathrm{n}=294)\end{array} \\
\text { No. }(\%)\end{array}$} & \multirow{2}{*}{$\begin{array}{c}\text { Crude OR } \\
(95 \% \mathrm{CI})\end{array}$} & \multirow{2}{*}{ p-value } & \multirow{2}{*}{$\begin{array}{c}\text { Statistical } \\
\text { power }\end{array}$} & \multicolumn{5}{|c|}{ Prior probability } & \multirow{2}{*}{$\begin{array}{c}\text { Adjusted } \\
\text { OR }(95 \% \mathrm{CI})\end{array}$} & \multirow{2}{*}{ p-value } \\
\hline & & & & & & 0.25 & 0.1 & 0.01 & 0.001 & 0.0001 & & \\
\hline \multicolumn{13}{|c|}{$\begin{array}{l}\text { rs3787016 } \\
\text { (HWE, P 0.247) }\end{array}$} \\
\hline \multicolumn{13}{|l|}{ Additive } \\
\hline GG & $90(24.5)$ & $92(31.3)$ & 1.00 & - & & & & & & & 1.00 & - \\
\hline $\mathrm{AG}$ & $148(40.2)$ & $136(46.3)$ & $\begin{array}{c}1.112 \\
(0.708-1.73)\end{array}$ & 0.646 & & & & & & & $\begin{array}{c}1.135 \\
(0.715-1.802)\end{array}$ & 0.592 \\
\hline AA & $130(35.3)$ & $66(22.4)$ & $\begin{array}{c}2.013 \\
(1.22-3.277)\end{array}$ & $0.005^{\star}$ & 0.118 & 0.110 & 0.271 & 0.804 & 0.976 & 0.998 & $\begin{array}{c}1.979 \\
(1.198-3.267)\end{array}$ & $0.008^{*}$ \\
\hline \multicolumn{13}{|l|}{ Dominant } \\
\hline GG & $90(24.5)$ & $92(31.3)$ & 1.00 & - & & & & & & & 1.00 & - \\
\hline $\mathrm{AG}+\mathrm{AA}$ & $278(75.5)$ & $202(68.7)$ & $\begin{array}{c}1.407 \\
(0.928-2.153)\end{array}$ & 0.108 & & & & & & & $\begin{array}{c}1.407 \\
(0.923-2.146)\end{array}$ & 0.113 \\
\hline \multicolumn{13}{|l|}{ Recessive } \\
\hline $\mathrm{GG}+\mathrm{AG}$ & $238(64.7)$ & $228(77.6)$ & 1.00 & - & & & & & & & 1.00 & - \\
\hline $\mathrm{AA}$ & $130(35.3)$ & $66(22.4)$ & $\begin{array}{c}1.887 \\
(1.249-2.855)\end{array}$ & $0.002^{\star}$ & 0.139 & 0.054 & 0.147 & 0.654 & 0.950 & 0.995 & $\begin{array}{c}1.847 \\
(1.222-2.793)\end{array}$ & $0.004^{*}$ \\
\hline
\end{tabular}

Notes: adjusted ORs with 95\% CIs were derived by a multivariate logistic regression model after adjusting for age, gender, smoking, drinking and helicobacter pylori status; statistical power was calculated using the number of observations in the group and the OR and p-values in this table; ${ }^{*}$ indicates $\mathrm{p}$-value $<0.05$; Abbreviations: OR-odds ratio; CI-confidence interval 


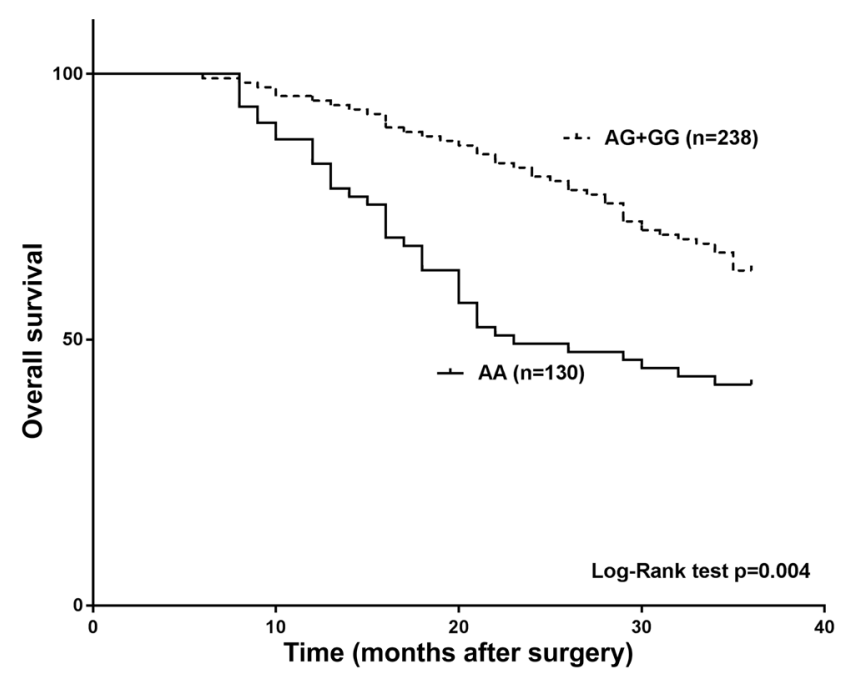

Figure 1. Survival plot of gastric cancer patients stratified by rs3787016 genotypes. Overall survival of gastric cancer patients carrying different POLR2E rs3787016 genotypes. p-values were calculated using the $\log$ rank test. mesenchymal transition (EMT), invasion, chemoresistance, and tumorigenesis in GC [24]. Moreover, several lncRNAs have been implicated as potential diagnostic biomarkers for GC, such as H19, UCA1, and LINC00152 [24]. For the present study, we have provided the first investigation about the associations of POLR2E rs3787016 polymorphism with the risk and prognosis of gastric cancer.

A previous study by Jin et al. provided the first evidence that the A allele of the POLR2E rs3787016 polymorphism was significantly associated with increased $\mathrm{PCa}$ risk $(\mathrm{OR}=1.19$, $95 \% \mathrm{CI}=1.11-1.27, \mathrm{p}=7.22 \times 10^{-7}$ ) in a Caucasian population via a meta-analysis of two existing PCa genome-wide association studies (GWAS) and their own replication study, which comprised 4,196 case patients and 5,007 control individuals [13]. Similar results have also been reported in the Chinese and Iranian populations $[14,16]$, albeit no significant association of rs3787016 with the PCa risk and standard prognostic parameters regarding PCa progression have been identified in the Serbian population [15]. Moreover, further studies have also been conducted for several other cancer types, and it

Table 3. Association of the POLR2E rs3787016 polymorphism with characteristics of 368 gastric cancer patients.

\begin{tabular}{|c|c|c|c|c|}
\hline & \multirow{2}{*}{ Total (\%) } & \multicolumn{3}{|c|}{ rs3787016 } \\
\hline & & GG, n (\%) & AG, n (\%) & AA, n (\%) \\
\hline \multicolumn{5}{|l|}{ Age } \\
\hline$\leq 60$ years & $204(55.4)$ & $50(13.6)$ & $88(23.9)$ & $66(17.9)$ \\
\hline$>60$ years & $164(44.6)$ & $40(10.9)$ & $60(16.3)$ & $64(17.4)$ \\
\hline OR (95\% CI) & & 1.00 & $0.852(0.411-1.791)$ & $1.212(0.571-2.629)$ \\
\hline $\mathrm{p}$-value & & - & 0.676 & 0.621 \\
\hline \multicolumn{5}{|l|}{ Gender } \\
\hline Male & $220(59.8)$ & $54(14.7)$ & $82(22.3)$ & $84(22.8)$ \\
\hline Female & $148(40.2)$ & $36(9.8)$ & $66(17.9)$ & $46(12.5)$ \\
\hline OR (95\% CI) & & 1.00 & $1.207(0.585-2.59)$ & $0.821(0.369-1.862)$ \\
\hline p-value & & - & 0.623 & 0.623 \\
\hline \multicolumn{5}{|l|}{ Smoking } \\
\hline Ever & $162(44.0)$ & $40(10.9)$ & $64(17.4)$ & $38(15.8)$ \\
\hline Never & $206(56.0)$ & $50(13.6)$ & $84(22.8)$ & $72(19.6)$ \\
\hline OR (95\% CI) & & 1.00 & $1.05(0.502-2.164)$ & $0.993(0.458-2.124)$ \\
\hline p-value & & - & 0.898 & 0.986 \\
\hline \multicolumn{5}{|l|}{ Drinking } \\
\hline Ever & $264(71.7)$ & $70(19.0)$ & $102(27.7)$ & $92(25.0)$ \\
\hline Never & $104(28.3)$ & $20(5.4)$ & $46(12.5)$ & $38(10.3)$ \\
\hline OR (95\% CI) & & 1.00 & $1.578(0.693-3.76)$ & $1.446(0.607-3.587)$ \\
\hline $\mathrm{p}$-value & & - & 0.295 & 0.412 \\
\hline \multicolumn{5}{|c|}{ Helicobacter pylori } \\
\hline Negative & $114(31.0)$ & $32(8.7)$ & $44(12.0)$ & $38(10.3)$ \\
\hline Positive & $254(69.0)$ & $58(15.8)$ & $104(28.3)$ & $92(25.0)$ \\
\hline OR (95\% CI) & & 1.00 & $1.304(0.616-2.914)$ & $1.336(0.607-2.889)$ \\
\hline p-value & & - & 0.509 & 0.484 \\
\hline \multicolumn{5}{|l|}{ Tumor size } \\
\hline$\geq 5 \mathrm{~cm}$ & $98(26.6)$ & $18(4.9)$ & $36(9.8)$ & $44(12.0)$ \\
\hline$<5 \mathrm{~cm}$ & $270(73.4)$ & $72(19.6)$ & $112(30.5)$ & $86(23.4)$ \\
\hline OR (95\% CI) & & 1.00 & $1.286(0.523-3.015)$ & $2.047(0.862-4.752)$ \\
\hline $\mathrm{p}$-value & & - & 0.585 & 0.113 \\
\hline
\end{tabular}


Table 3. Continued ...

\begin{tabular}{|c|c|c|c|c|}
\hline & \multirow{2}{*}{ Total (\%) } & \multicolumn{3}{|c|}{ rs3787016 } \\
\hline & & GG, n (\%) & AG, n (\%) & AA, n (\%) \\
\hline \multicolumn{5}{|l|}{ Histologic grade } \\
\hline Well+moderate & $196(53.3)$ & $58(15.8)$ & $84(22.8)$ & $54(14.7)$ \\
\hline Poor & $172(46.7)$ & $32(8.7)$ & $64(17.4)$ & $76(20.7)$ \\
\hline OR (95\% CI) & & 1.00 & $1.381(0.659-2.914)$ & $2.551(1.177-5.436)$ \\
\hline $\mathrm{p}$-value & & - & 0.407 & $0.018^{*}$ \\
\hline \multicolumn{5}{|l|}{ TNM stage } \\
\hline I-II & $144(39.1)$ & $44(12.0)$ & $64(17.4)$ & $36(9.8)$ \\
\hline III-IV & $224(60.9)$ & $46(12.5)$ & $84(22.8)$ & $94(25.5)$ \\
\hline OR $(95 \% \mathrm{CI})$ & & 1.00 & $1.255(0.609-2.6)$ & $2.5(1.107-5.391)$ \\
\hline $\mathrm{p}$-value & & - & 0.549 & $0.023^{*}$ \\
\hline \multicolumn{5}{|l|}{ Depth of invasion } \\
\hline $\mathrm{T} 1+\mathrm{T} 2$ & $108(29.3)$ & $36(9.8)$ & $46(12.5)$ & $26(7.1)$ \\
\hline $\mathrm{T} 3+\mathrm{T} 4$ & $260(70.7)$ & $54(14.7)$ & $102(27.7)$ & $104(28.3)$ \\
\hline OR (95\% CI) & & 1.00 & $1.478(0.667-3.227)$ & $2.667(1.161-5.929)$ \\
\hline $\mathrm{p}$-value & & - & 0.321 & $0.022^{*}$ \\
\hline \multicolumn{5}{|c|}{ Lymph node metastasis } \\
\hline Negative & $126(34.2)$ & $42(11.4)$ & $54(14.7)$ & $30(8.2)$ \\
\hline Positive & $242(65.8)$ & $48(13.0)$ & $94(25.5)$ & $100(27.2)$ \\
\hline OR $(95 \% \mathrm{CI})$ & & 1.00 & $1.523(0.725-3.209)$ & $2.917(1.238-6.707)$ \\
\hline $\mathrm{p}$-value & & - & 0.272 & $0.01^{*}$ \\
\hline \multicolumn{5}{|l|}{ Distant metastasis } \\
\hline Negative & $300(81.5)$ & $76(20.7)$ & $128(34.8)$ & $76(20.7)$ \\
\hline Positive & $68(18.5)$ & $14(3.8)$ & $20(5.4)$ & $34(9.2)$ \\
\hline OR $(95 \%$ CI $)$ & & 1.00 & $0.848(0.318-2.229)$ & $2.429(0.958-6.128)$ \\
\hline $\mathrm{p}$-value & & - & 0.758 & 0.074 \\
\hline
\end{tabular}

Note: ${ }^{*}$ indicates p-value $<0.05$; Abbreviations: OR-odds ratio; CI-confidence interval.

has been reported that $P O L R 2 E$ rs 3787016 polymorphism is significantly associated with the risk for breast cancer, cervical cancer, esophageal cancer, and papillary thyroid carcinoma [20-23], but not for lung cancer, liver cancer, and glioma $[17,22]$. Our results demonstrated that the genotype AA of rs3787016 is significantly associated with increased gastric cancer risk, which is consistent with the findings of most of the related previous studies. Interestingly, although $H$. pylori infection is considered as the main risk factor for gastric cancer, the correlation between the rs3787016 polymorphism and gastric cancer risk remained statistically significant even after adjusting for several variables, including $H$. pylori infection, which indicates that the POLR2E rs3787016 polymorphism is an independent risk factor for gastric cancer.

Accumulating evidence has suggested that SNPs in lncRNAs can be applied as potential prognostic biomarkers for GC [24]. Li et al. reported that a G allele at the HOX transcript antisense RNA (HOTAIR) rs17720428 (T>G) locus was significantly associated with poor OS of gastric cancer patients [25]. Individuals with T3 gastric adenocarcinoma carrying the genotype AG of H19 rs2839698 polymorphism showed significantly lower risks of recurrence and death when compared with those carrying the genotype GG [26]. To date, the prognostic role of POLR2E rs3787016 polymorphism has
Table 4. Univariate Cox regression analyses of overall survival in 368 gastric cancer patients.

\begin{tabular}{lcc}
\hline & \multicolumn{2}{c}{ Univariate analysis } \\
\cline { 2 - 3 } & HR $(\mathbf{9 5 \%}$ CI $)$ & p-value \\
\hline rs3787016 (AA genotype) & $2.136(1.381-3.302)$ & $0.001^{*}$ \\
Age ( $>60$ years) & $1.03(0.666-1.594)$ & 0.894 \\
Gender (male) & $1.14(0.735-1.766)$ & 0.559 \\
Smoking (ever) & $1.191(0.772-1.837)$ & 0.429 \\
Drinking (ever) & $1.523(0.902-2.569)$ & 0.115 \\
Helicobacter pylori (positive) & $1.381(0.841-2.268)$ & 0.202 \\
Tumor size $(\geq 5$ cm) & $1.548(0.977-2.456)$ & 0.063 \\
Histologic grade (poor) & $1.614(1.044-2.495)$ & $0.031^{\star}$ \\
TNM stage (III-IV) & $2.458(1.47-4.111)$ & $0.001^{\star}$ \\
Depth of invasion (T3-T4) & $1.444(0.879-2.373)$ & 0.146 \\
Lymph node metastasis (positive) & $1.693(1.031-2.782)$ & $0.037^{\star}$ \\
Distant metastasis (positive) & $1.294(0.767-2.183)$ & 0.334 \\
\hline
\end{tabular}

Note: ${ }^{*}$ indicates $p$-value $<0.05$. Abbreviations: HR-hazard ratio; CI-confidence interval

not been investigated for all cancer types. We found that the genotype AA of rs3787016 was significantly associated with more aggressive clinicopathological characteristics of gastric cancer patients. In fact, our multivariate analysis revealed that rs3787016 was a prognostic biomarker independent 
Table 5. Multivariate Cox regression analyses of overall survival in 368 gastric cancer patients.

\begin{tabular}{lcc}
\hline & \multicolumn{2}{c}{ Multivariate analysis } \\
\cline { 2 - 3 } & HR (95\% CI) & p-value \\
\hline rs3787016 (AA genotype) & $1.668(1.058-2.631)$ & $0.028^{*}$ \\
Histologic grade (poor) & $1.481(0.948-2.314)$ & 0.085 \\
TNM stage (III-IV) & $2.215(1.314-3.732)$ & $0.003^{*}$ \\
Lymph node metastasis (positive) & $1.61(0.97-2.673)$ & 0.065 \\
\hline
\end{tabular}

Note: ${ }^{*}$ indicates p-value $<0.05$. Abbreviations: HR-hazard ratio; CI-confidence interval.

of several adjusted well-known prognostic parameters for gastric cancer, including the histological grade, TNM stage, and lymph node metastasis.

However, the underlying biological mechanisms for the effects of rs3787016 on GC susceptibility and prognosis remain unclear. It also remains unclear whether the POLR2E rs3787016 polymorphism can influence its gene expression and function, as several other previously reported SNPs. Yang et al. determined the anti-apoptotic role of POLR2Emediating protein $(R M P)$ in the proliferation and growth of hepatocellular carcinoma (HCC) cells through cell growth and colony formation assays [26]. Based on more evidence reported by Wan et al. that RMP could promote intrahepatic cholangiocarcinoma (ICC) tumorigenesis, metastasis, and drug resistance by competing with the nuclear factor E2-related factor 2 (NRF2) for Kelch-like ECH-associated protein 1 (KEAP1) binding, which induced the downstream transactivation of antioxidant genes [27]. We hypothesized that the rs3787016 polymorphism could modulate the splice processes of POLR2E, which may lead to a dysfunctional POLR2E; therefore, it would affect the transcriptional activity of RMP in normal cells.

As a case-control study, although with the advantages of being capable of studying rare conditions related to a certain disease, as well as looking at multiple risk factors simultaneously, we may still need to further request a larger sample size, a prospective study for the development of cancer due to the polymorphism, a multi-center involvement, and more research on molecular mechanisms to better understand the nature of the relationship between gastric cancer and the polymorphism, thus to confirm the findings of this preliminary study.

In conclusion, in our study, we found the first evidence that the polymorphism of POLR2E rs3787016 can serve as a biomarker that affects the susceptibility to and the prognosis of gastric cancer in a Chinese population. Individuals carrying the AA genotype of rs3787016 showed a significantly higher risk of gastric cancer. For the gastric cancer patients, the AA genotype of rs3787016 was significantly associated with extremely poor OS and with several clinicopathological characteristics such as poorly differentiated type, advanced TNM stage, higher depth of invasion, and positive lymph node metastasis.
Acknowledgments: We would like to thank Pro. H. X and Mr. P. $\mathrm{T}$ for their help in the collection of clinical and demographic data. This study was supported by grants from the Science and Technology Program of the Education Department of Sichuan province (18ZB0208) and the Science and Technology Program of the eNanchong government (18SXHZ0237).

\section{References}

[1] BRAY F, FERLAY J, SOERJOMATARAM I, SIEGEL RL, TORRE LA et al. Global cancer statistics 2018: GLOBOCAN estimates of incidence and mortality worldwide for 36 cancers in 185 countries. CA Cancer J Clin 2020; 70: 313. https:// doi.org/10.3322/caac.21609

[2] CHEN W, ZHENG R, BAADE PD, ZHANG S, ZENG H et al. Cancer statistics in China, 2015. CA Cancer J Clin 2016; 66: 115-132. https://doi.org/10.3322/caac.21338

[3] PLUMMER M, FRANCESCHI S, VIGNAT J, FORMAN D, DE MARTEL C. Global burden of gastric cancer attributable to Helicobacter pylori. Int J Cancer 2015; 136: 487-490. https://doi.org/10.1002/ijc.28999

[4] IARC WORKING GROUP ON THE EVALUATION OF CARCINOGENIC RISKS TO HUMANS. Personal habits and indoor combustions. Volume $100 \mathrm{E}$. A review of human carcinogens. IARC Monogr Eval Carcinog Risks Hum 2012; 100: 1-538.

[5] LONG ZW, YU HM, WANG YN, LIU D, CHEN YZ et al. Association of IL-17 polymorphisms with gastric cancer risk in Asian populations. World J Gastroenterol 2015; 21: 5707 5718. https://doi.org/10.3748/wjg.v21.i18.5707

[6] ZENG H, CHEN W, ZHENG R, ZHANG S, JI JS et al. Changing cancer survival in China during 2003-15: a pooled analysis of 17 population-based cancer registries. Lancet Glob Health 2018; 6: e555-e567. https://doi.org/10.1016/ S2214-109X(18)30127-X

[7] YANG G, LU X, YUAN L. LncRNA: a link between RNA and cancer. Biochim Biophys Acta 2014; 1839: 1097-1109. https://doi.org/10.1016/j.bbagrm.2014.08.012

[8] PAN W, LIU L, WEI J, GE Y, ZHANG J et al. A functional lncRNA HOTAIR genetic variant contributes to gastric cancer susceptibility. Mol Carcinog 2016; 55: 90-96. https://doi. org/10.1002/mc.22261

[9] ZHANG X, RICE K, WANG Y, CHEN W, ZHONG Y et al. Maternally expressed gene 3 (MEG3) noncoding ribonucleic acid: isoform structure, expression, and functions. Endocrinology 2010; 151: 939-947. https://doi.org/10.1210/en.20090657

[10] LIU X, ZHAO Y, LI Y, ZHANG J. Quantitative assessment of lncRNA H19 polymorphisms and cancer risk: a meta-analysis based on 48,166 subjects. Artif Cells Nanomed Biotechnol 2020; 48: 15-27. https://doi.org/10.1080/21691401.2019. 1699804

[11] YANG ML, HUANG Z, WANG Q, CHEN HH, MA SN et al. The association of polymorphisms in lncRNA-H19 with hepatocellular cancer risk and prognosis. Biosci Rep 2018; 38: BSR20171652. https://doi.org/10.1042/BSR20171652 
[12] WANG W, YANG Q, HUANG Q, ZHANG H, ZHANG Z et al. The rs2839698 Single Nucleotide Polymorphism of lncRNA H19 is Associated with Post-Operative Prognosis in T3 Gastric Adenocarcinoma. Clin Lab 2018; 64: 105-112. https://doi.org/10.7754/Clin.Lab.2017.170706

[13] JIN G, SUN J, ISAACS SD, WILEY KE, KIM ST et al. Human polymorphisms at long non-coding RNAs (lncRNAs) and association with prostate cancer risk. Carcinogenesis 2011; 32: 1655-1659. https://doi.org/10.1093/carcin/bgr187

[14] SATTARIFARD H, HASHEMI M, HASSANZAREI S, BASIRI A, NAROUIE B et al. Long non-coding RNA POLR2E gene polymorphisms increased the risk of prostate cancer in a sample of the Iranian population. Nucleosides Nucleotides Nucleic Acids 2019; 38: 1-11. https://doi.org/10.1080/15257 770.2017 .1391394

[15] NIKOLIĆ ZZ, BRAJUŠKOVIĆ GN, PAVIĆEVIĆ DLJ, KOJIĆ AS, VUKOTIĆ VD et al. Assessment of possible association between rs3787016 and prostate cancer risk in Serbian population. Int J Clin Exp Med. 2013; 6: 57-66.

[16] CAO DL, GU CY, ZHU Y, DAI B, ZHANG HL et al. Polymorphisms at long non-coding RNAs and prostate cancer risk in an eastern Chinese population. Prostate Cancer Prostatic Dis 2014; 17: 315-319. https://doi.org/10.1038/ pcan.2014.34

[17] CHEN B, WANG S, MA G, HAN J, ZHANG J et al. The association of POLR2E rs3787016 polymorphism and cancer risk: a Chinese case-control study and meta-analysis. Biosci Rep 2018; 38: BSR20180853. https://doi.org/10.1042/ BSR20180853

[18] CHEN B, JIAO Y, YAOLONG F, LI T, LIU Y et al. The POLR2E rs3787016 polymorphism is strongly associated with the risk of female breast and cervical cancer. Pathol Res Pract 2019; 215: 1061-1065. https://doi.org/10.1016/j. prp.2019.02.015

[19] XU T, HU XX, LIU XX, WANG HJ, LIN K et al. Association between SNPs in Long Non-coding RNAs and the Risk of Female Breast Cancer in a Chinese Population. J Cancer 2017; 8: 1162-1169. https://doi.org/10.7150/jca.18055
[20] KANG M, SANG Y, GU H, ZHENG L, WANG L et al. Long noncoding RNAs POLR2E rs3787016 C/T and HULC rs7763881 A/C polymorphisms are associated with decreased risk of esophageal cancer. Tumour Biol 2015; 36: 6401-6408. https://doi.org/10.1007/s13277-015-3328-Z

[21] CHEN B, LI J, YI C, JIAO Y, GU X et al. Long non-coding RNA POLR2E rs3787016 is associated with the risk of papillary thyroid carcinoma in Chinese population. Pathol Res Pract 2018; 214: 1040-1044. https://doi.org/10.1016/j. prp.2018.04.008

[22] DENG Y, ZHOU L, LI N, WANG M, YAO L et al. Impact of four lncRNA polymorphisms (rs2151280, rs7763881, rs1136410, and rs3787016) on glioma risk and prognosis: A case-control study. Mol Carcinog 2019; 58: 2218-2229. https://doi.org/10.1002/mc.23110

[23] BHAN A, SOLEIMANI M, MANDAL SS. Long Noncoding RNA and Cancer: A New Paradigm. Cancer Res 2017; 77: 3965-3981. https://doi.org/10.1158/0008-5472.CAN-162634

[24] FATTAHI S, KOSARI-MONFARED M, GOLPOUR M, EMAMI Z, GHASEMIYAN $M$ et al. LncRNAs as potential diagnostic and prognostic biomarkers in gastric cancer: A novel approach to personalized medicine. J Cell Physiol 2020; 235: 3189-3206. https://doi.org/10.1002/jcp.29260

[25] LI Y, ZHANG Z, YANG Y, MA J. Long Noncoding RNA HOX Transcript Antisense RNA Gene rs17720428 Single Nucleotide Polymorphism Is Associated with Gastric Cancer Risk and Prognosis. Genet Test Mol Biomarkers 2020; 24: 38-46. https://doi.org/10.1089/gtmb.2019.0140

[26] YANG H, GU J, ZHENG Q, LI M, LIAN X et al. RPB5-mediating protein is required for the proliferation of hepatocellular carcinoma cells. J Biol Chem 2011; 286: 11865-11874. https://doi.org/10.1074/jbc.M110.136929

[27] WAN ZH, JIANG TY, SHI YY, PAN YF, LIN YK et al. RPB5Mediating Protein Promotes Cholangiocarcinoma Tumorigenesis and Drug Resistance by Competing With NRF2 for KEAP1 Binding. Hepatology 2020; 71: 2005-2022. https:// doi.org/10.1002/hep.30962 